\title{
A Research on the Development of Financial Markets in Agriculture and Rural Areas by Commercial Banks Based on Rural Revitalization Strategy
}

\author{
Jie Xiao" ${ }^{1}$, Shan Jian', Jiehua Xie ${ }^{1}$, Zepeng Chen ${ }^{1}$, and Chengqing $\mathrm{Li}^{1,}$ * \\ ${ }^{1}$ ICBC Guangdong Branch, Guangzhou, China \\ ${ }^{2}$ Guangdong University of Finance \& Economics, Guangzhou, China
}

Keywords: Commercial bank; Rural revitalization; Financial market; Measures

\begin{abstract}
At present, the investment and development in rural China by China's banking industry is seriously lagging. The introduction and implementation of Rural Revitalization Strategy Plan, which is one of the major strategies for building China into a great modern economic country, has brought the most important transition development opportunity to the agricultural and rural economy. It has also brought broad financial market space and will have a profound impact on the bank's business development. Practice has proved that economic development drives the development of banking, while banking stimulates economic development in turn. Therefore, under the strategic plan of rural revitalization, commercial bank should participate actively, so as to create new advantages for promoting the development of rural revitalization and promote their own operations to a higher level. To this end, this article, through further analyzing the rural financial market situation and the problems existing in the bank's support for rural revitalization, proposes specific development measures for bank supporting for rural revitalization to strengthen China's agricultural and rural construction.
\end{abstract}

\section{Rural Revitalization Strategy and Financial Support}

\subsection{Rural revitalization strategy and agricultural development}

Issues relating to agriculture, rural areas and rural people are fundamental to China as they directly concern our country's stability and our people's well-being, and these issues are also shortcomings of China's economic development. China is in the stage of decisive victory in building a moderately prosperous society in all respects, great efforts should be made to lengthen short stave and strengthen areas of weakness. For this reason, addressing these issues should have a central place on the work agenda of the Party and rural revitalization should be promoted fully. On Oct 18th 2017, Comrade Xi Jinping proposed rural revitalization strategy in the report of the 19th National Congress of the Communist Party of China, that the participation and benefit of farmers in industrial development should be improved continuously, problems of rural industry and peasant employment should be solved completely, so that to ensure the local people's long-term income stable and increased, and their living and working in peace and contentment. In Sept. 2018, Rural Revitalization Strategy Plan (2018-2022) was released by CPC Central Committee and State Council, which made a phased plan for implementing the rural revitalization strategy, formulating clearly that by 2020 a moderately prosperous society in all respects will be built; by 2022 the target task of the 20th National Congress of the Communist Party of China, refining the focus of the work and policy measures, deploying major projects, major plan, major action, ensuring rural revitalization strategy be implemented. Rural Revitalization Strategy Plan proposed that by 2020, the institutional framework and policy system of rural revitalization should have been basically formed; thoughts and measures of rural revitalization in various regions and departments should have been established; the goal of building a moderately prosperous society in all respects should have been realized on schedule. By 2022, the institutional framework and policy system of rural revitalization should have been initially improved. A set of unique models and experiences of rural revitalization should have been explored and formed, and phased success of rural revitalization should have been achieved. By 2035, decisive progress should have been made, modernization of 
agriculture and rural areas have been basically realized. By 2050, rural areas should have been full revitalized, which should have strong agriculture, a beautiful countryside and well-off farmers.

In recent years, China's agriculture has maintained steady development. Although the growth of gross agricultural production is still lower than the overall growth rate, the growth of investment has been accelerated in recent years, the foundation of agriculture development has been constantly solid. In 2018, gross domestic product was 90.0309 trillion yuan, an increase of 6.6 percent over the figure for 2017. Added value of primary industry was 6.4734 trillion yuan, an increase of 3.5 percent over the figure for 2017, whose growth rate was lower than secondary industry and tertiary industry. Fixed asset investment (farmer excluded) was 63.5636 trillion yuan, an increase of 5.9 percent over the figure for 2017. Investment in primary industry was increased by 12.9 percent, accelerated by 1.1 percent, the growth of which was higher than secondary industry and tertiary industry. In 2018, China's total grain output was 657.89 million tons, although decreased by 0.6 percent than the year 2017, which was still in a historical high productive year and had maintained more than 650 million tons for four consecutive years. The productivity of pork, beef and mutton was 85.17 million tons, which was slightly lower 0.3 percent than the year 2017 and remained stable overall. Per capita disposable income of rural residents was 14.617 thousand yuan, a nominal increase of 8.8 percent over the previous year, the growth of rural residents' income was faster than residents in city. In 2017, a total of 2.8 billion people experienced leisure agriculture and rural tourism, rural operating income had reached 700 billion. In recent years, China's agricultural and rural economy has maintained a stable and good development trend, the growth of fixed asset investment has been accelerated, the income level of rural residents has grown rapidly year by year. In this respect, the expansion of the agricultural and rural markets has deep potential and huge space.

\subsection{Policies of Finance Supporting Rural Areas and Conditions of Bank Development}

In February 2019, guideline of finance supporting rural revitalization was jointly issued by five departments including People's Bank of China, which clarified the goal of finance supporting rural revitalization in the corresponding stage. By 2020, it should be ensured that targeted poverty alleviation by finance should be constantly enhanced, the financial resources for supporting agriculture should be constantly increased, financial services in rural areas should be constantly improved, and management of financial institutions related agriculture and the ability to support agriculture should be apparently improved. In the medium and long term, the establishment of a modern financial system in rural areas should be improved, which should cover multiple levels and wide regions, be sustainable, and contain moderate competition, orderly innovation and controllable risks. Ultimately, rational and orderly allocation of financial resources and the equalization of financial services between urban and rural areas will be realized. It should also insist on operating by market-oriented, motivating by institutional reform, guiding by policy support, regarding risk prevention and control as bottom line, focusing on key fields, deepening reform and innovation, establishing and improving the market system, organizational system and product system, in which finance supports rural revitalization, so that to promote the return of financial resources back to rural areas. Measures should be proposed to effectively improve the efficiency and level of financial service for rural revitalization.

In recent years, the growth of domestic banking industry has slowed down, profitability has declined, the amount of non-performing loans has remained high, and pressures of bank operating have continued to increase; In addition, China is currently in the shifting period of the old and new kinetic energy of the economy [1]. Since 2018, under the influence of the changeable external environment such as the strengthening of the US dollar and China-US trade friction, it has become the new normal of commercial banks, that the growth of commercial banks has slowed down, the space for profit improvement is limit, the quality of assets is under pressure, the growth of new business is limited [2]. With the steady and positive development of the agricultural and rural economy and the good opening of rural revitalization strategy, which has become a new driving force for China's economic growth, the development potential of agriculture and rural areas has 
been reflected. Together with the government's top-level policies for rural revitalization and local government's supporting policies, further it has spawned a large number of policy dividends and the market space of banks, which has created huge and effective financial needs. According to estimation by the Ministry of Agriculture and Rural Affairs, the total funding needs for rural revitalization is above 7 trillion yuan. In this respect, rural revitalization will bring a broad market space for the development of the financial industry, and will also inject new business vitality into commercial banks in the new round of business development.

\section{The Existing Problems of Banks in Supporting Rural Revitalization Development}

Finance is the core of modern market economy, and commercial banks are the most important part of modern finance. In the market economy, banking development has a close relationship with economic growth. Empirical analysis shows that the interaction between banking development and economic growth is mutual. Economic growth promotes the development of the banking industry, and in turn the development of the banking industry has a considerable contribution to the growth of economy, between which there is a positive correlation [3]. Due to the huge demand of funds for rural revitalization and the variety of supporting services, without the full participation of the banking, it is difficult to carry out rural revitalization well. In this case, through the resource-directed allocation role of the banking industry, more financial resources can be allocated to key fields and weak links in rural areas, which can better meet the diverse and multi-level financial demand for rural revitalization and promote the integration development of urban and rural areas. However, at present commercial banks still have many shortcomings and inadequacies in financial support for agriculture and rural areas, which affects the adjustment of financial resources.

\subsection{Insufficient attention to agricultural and rural financial markets in history}

Due to the extreme imbalance of agricultural and rural economic development, coupled with the small amount of rural economy, especially the historical asymmetry of information in agricultural and rural financial markets, high transaction costs and the lack of secured collateral, the main development of major banking institutions For the expansion of the core areas of the city, few commercial banking institutions have entered the agricultural and rural financial markets, thus failing to understand the development trend of agriculture and rural areas, and still paying attention to agricultural and rural financial markets. At present, agricultural and rural financial markets are dominated by agricultural banks and rural credit cooperatives, and most commercial banks are basically in the agricultural and rural markets. In recent years, with the acceleration of the development of agricultural industrialization, the development of rural economy and the rapid growth of farmers' income have enabled the effective growth of financial demand; In addition, with the rapid development of financial technology, integrating data information through technology and building a big data analysis platform can reduce the risk of information asymmetry and reduce operating costs. To this end, individual commercial banks have begun to pay attention to agricultural and rural financial markets since last year.

\subsection{Weak operating capacity of banking institution at county level and below}

At present, the commercial banks in the agricultural and rural areas are mainly concentrated in the county towns. There are few banking institutions at the township level. The banking institutions in the county towns basically carry out business around the county towns. It is difficult to extend the business to the township level. In addition, commercial banking institutions have not paid much attention to the agricultural and rural financial markets in history, and their resources are less. The county economy is underdeveloped and the talents are poorly matched. It is difficult to attract better financial talents. For this reason, the characteristic that banking financial institution's personnel and service are concentrated in urban areas are obvious. Moreover, the banking institutions at the county level and below are subject to the aging of personnel structure, low academic level, failure to update business skills and limited business sense. There are many inherent shortcomings, but the bank's 
superior departments provide less effective guidance and training, and personnel who seriously failed to effectively flow are solidified, which form a stimulus, causing that the bank's operating efficiency is not high, operating efficiency is poor, thus further weakening the ability to operate.

\subsection{A large business short board formed by agricultural and rural markets}

At present, county-level sub-branches of commercial banks are under the condition full of problems, such as heavy historical burdens, slow development of operation, low profitability and frequent occurrence of accidents and cases. The financial market at or below the county level is still the shortcoming of commercial banks. Its management and risk control have always been the weak link of bank management and control. Due to the weak characteristics of the rural economy, it is easy to increase the risk of credit, and the overall operating environment of the agriculture and rural areas is relatively complex. The quality of the banking employees is different, and the degree of unevenness is higher, which leads to the higher probability of operational risk and compliance risk. To a certain extent, a huge operating difficulty has been caused to the banking institution.

\subsection{Lack of financial products that adapt to the characteristics of the agricultural and rural markets}

At present, the current situation of financial services for agricultural and rural areas is still far from the reality of China's economic development and the demands of urban and rural residents. In the past, the focus of commercial bank development was on cities. Its products were mainly designed to suit the characteristics of urban financial development. In recent years, the rapid development of agricultural and rural economy has driven the demand for financial services to be more vigorous, and the demand situation has also undergone new changes, such as the transformation of agricultural industry to characteristic and large-scale development, strong demand of large agricultural loans; Framers' income has been increased, which lead to the growth of demand for financial services such as consumer credit, investment and financial advisory, precious metals and financial derivatives transactions; The investment in fixed assets in agriculture and rural areas has increased, and the financial demand for agricultural and rural infrastructure construction has increased; The improvement and popularization of modern mobile Internet and intelligent terminals will accelerate the transformation and application of traditional physical outlets of bank. However, at present, banking institutions are not targeted at agricultural and rural financial services. The products and services that are suitable for the characteristics of agriculture and rural areas and meet the characteristics of agricultural industrialization development are few. Many financial products and services suitable for large cities cannot effectively meet the real financial demands of rural revitalization strategies.

\subsection{Insufficient development of financial services channels}

Although a large number of outlets have been completed by commercial banks in cities, most commercial banks lack the incentive to add institutional outlets in rural areas. At present, banking institutions still rely on basic credit business and traditional settlement services in agricultural and rural areas. The business is mainly concentrated in the county, which rarely sink to the township level, and the bank's comprehensive financial services and value-added products are relatively insufficient; the banking institution outlets and intelligent service facilities are inadequately laid out, and obstacles to financial services are large. In particular, new-type business entities such as family farms, large professional households, and farmer cooperatives that have developed well in recent years still need financial institutions to provide professional financial guidance and services in production organization, corporate governance, financial regulation, and market development. Service channels of banking industry have not yet effectively extended to the agricultural and rural markets.

\section{Measures of Supporting Rural Revitalization by Banks}

The advantage of commercial banks lies in their ability to reallocate financial resources. 
Compared with rural credit cooperatives, commercial banks have obvious advantages, that commercial banks have large scale of operations, full range of products, high service capacity, and high level of operation and risk management. However, its main shortcoming lies in the lack of investment in the agricultural and rural markets in the early stage and the lack of market awareness, which has caused the dilemma of agricultural and rural financial development. At present, the guideline of finance serving rural revitalization has been issued by PBOC, which has proposed a series of measures. However, the key of implementation of all measures lies in institutions and people [4]. The institutional advantages of commercial banks are obvious, what is needed now is to reverse the top-level management ideas, and to mobilize the enthusiasm and initiative of local operator in agriculture and rural areas by system and investment of resources, in order to better carry out their work, serve and support rural revitalization [5].

\subsection{Transforming operating thoughts of financial development in agriculture and rural areas}

With the comprehensive and in-depth implementation of the rural revitalization strategy, the formation of modern agricultural industrial system will be accelerated, the construction of rural infrastructure will be increased continuously, the income level and living standards of farmers will be raised constantly, and there is a broad market space for agricultural and rural finance. To this end, financial support for rural revitalization is on the one hand the requirements of economic development, and on the other hand is a major opportunity for financial institutions to accelerate development. Under this circumstance, commercial banks must change the development concept of agricultural and rural finance in the past, conform to and clarify the characteristics and trends of the financial needs of the current agricultural and rural economy, and change to the development concept of "market and customer-centered". Assess the situation and Initially take the whole new ideas of agricultural and rural finance development, timely adjust its own business strategy, make a top-level design strategy, set phased development goals in a targeted manner, further increase financial supply, and allocate more financial resources to the key areas and weak links of agriculture and rural areas, so as to promote the overall revitalization of rural areas [6].

\subsection{Improvement of the competitiveness of county-level channels}

\subsubsection{Expansion construction of county-level channel}

Commercial banks should pay much attention to the construction of county-level channels, continue to increase investment in county-level channels, strengthen the rational distribution of physical network and intelligent terminals, recruit college students to county-level institutions every year, and provide regular training and rotation so as to improve outlets services. In view of the current high popularity of mobile communications and the opportunities brought about by the development of technology finance, the development of mobile channel banking business should be accelerated on order to compensate for the shortage of physical outlets. Through taking full advantage of its own technology and talents, online financial products suitable for rural areas should be developed constantly, and a combination of the advantages of traditional physical outlets and the Internet electronic channels should be made. It is also possible to provide basic financial services by cooperating with third parties to arrange electronic machines and tools such as transfer telephones, POS machines, and two-dimensional code collection and payment, in places with large transactions such as rural supermarkets and professional markets.

\subsubsection{Establishment of an assessment system adapted to agricultural and rural finance}

Agricultural and rural financial markets are different from other types of financial markets, and the differences are larger. Therefore, banking institutions should change the original unified assessment system, and combine the characteristics of agricultural and rural financial markets in different regions, rebuild a rational assessment mechanism and joint accountability mechanism in agricultural and rural market according to regional characteristics, and optimize the responsibilities of relevant departments and personnel of the bank, try the fault-tolerant mechanism, establish the evaluation index of the bank's adaptation to rural revitalization strategy, and strengthen the linkage 
between the assessment results and business authorization, resource allocation, team rewards and punishments, establish a salary distribution mechanism of value contribution and performance-oriented, so as to enhance the whole bank's enthusiasm and initiative to serve the rural revitalization.

\subsubsection{Adaption to resource inclination allocation}

Operating resources should be allocated appropriately to the agricultural and rural financial sector to ensure effective and sustained large-scale resource investment, and give priority to meeting the needs of "people, wealth, and material” for finance serving rural revitalization strategy. At the same time, relevant measures should be taken to ensure that the bank's resources can be accurately invested in relevant fields, the expected results can be achieved, and a basic guarantee mechanism can be established. At the same time, considering the fact that the living conditions, traffic conditions and working environment of the county employees are inferior to the actual situation of the urban employees, some of the cost resources should be inclined to the county branch employees, and appropriate allowance should be provided by giving appropriate discounts on product pricing, so as to help county employees to relieve their worries about life.

\subsubsection{Strengthen the construction of talent team}

Human resources are the first element of market expansion of banking institutions. For this reason, banks must strengthen human resource allocation, staff training, rational allocation of staff, and mobilize the enthusiasm and vitality of employees. Strengthen the refined management of employees, recruit localized personnel as much as possible, reduce the irrational flow of personnel, establish a promotion and withdrawal mechanism for customer relationship managers, a training mechanism for talents, and an exchange mechanism, provide professional training for lower-ranking managers; Widen local employees' field of vision by various ways, such as regular exchange of personnel from the higher authorities, and "home delivery" teaching. Effectively improve the overall quality of the team, improve the bank's customer service and market competitiveness. At the same time, the total balance accounting of labor resources of county institutions can be implemented, and the vertical and horizontal flow of personnel can be implemented through various methods such as recruitment and personnel exchange. When the opportunities and conditions for personal development of employees are fully created, the contradiction between business growth and shortage of personnel and unreasonable structure of personnel can be solved.

\subsection{Innovation of products and service system}

\subsubsection{Innovation of products system}

Financial product innovation should be actively and steadily carried out, financial service capacity of supporting county economic development should be initially upgraded. Combining the characteristics of agricultural and rural economy, personalized financial products and service programs should be designed purposefully, such as the design of plant construction and large agricultural machinery mortgage, poultry pens and living poultry mortgages, movable property pledges, warehouse receipts and accounts receivable pledge, agricultural insurance policy financing, to solve the problem of insufficient funds for agricultural and rural economic development. At the same time, according to the financial services needs of agricultural and rural financial investment, wealth management, precious metals, credit cards and financial derivatives transactions, a differentiated financial product system should be created, a customer tiered system should be established, refined management should be implemented, pricing should be differentiated. For seasonal characteristics of agricultural production, financial services that meet different needs should be provided.

\subsubsection{Innovation of service system}

According to different market conditions and risk characteristics, appropriate decentralization of 
credit approval authority and differentiated authorization for different credit business types and quotas. A certain amount of low-risk credit business approval authority can be sunk to county-level institutions. Appropriately simplify the loan approval process and innovate the internal credit management mechanism of banking institutions that adapt to the characteristics of agriculture and rural areas.

The efficiency of business handling in the agricultural and rural markets should be improved, paperless management and network management should be comprehensively implemented, the running time of staffs of agricultural and rural banking institutions should be reduced, and the efficiency of banking operations in the agricultural and rural markets should be effectively improved. At the same time, the corresponding operation mechanism can be established, and the whole process of each business can be monitored and completed in a limited time, so as to improve business efficiency comprehensively.

\subsection{Acceleration of the development of agricultural and rural financial business}

\subsubsection{Actively support for the construction of agricultural and rural infrastructure}

Agricultural and rural infrastructure, transportation infrastructure and urban land management projects should be actively supported. People's livelihood project should be selected and supported, such as commercial operation, old city transformation with sufficient cash flow, waste-to-energy, sewage treatment, water-saving and cleaning. Financial services for key projects should be actively explored, such as rural production materials reserves, agricultural product circulation, rural professional wholesale markets, schools, hospitals, with financial support to provide credit support.

\subsubsection{Acceleration of the layout of agricultural industry chain}

Focusing on the layout of the agricultural industrial chain, financial services for leading enterprises in industrialization should be increased. By cooperating with leading enterprises, we will accelerate the agricultural industrial chain should be accelerated to join in and provide customers with financial solutions integrating credit financing, payment settlement and wealth management. Supporting the majority of new agricultural business entities to become stronger and better, and cultivating new business sources. Supporting the development of leisure and sightseeing agriculture, rural tourism, rural handicrafts and local products services, and actively investing in personal production and operation loans.

\subsubsection{Improvement of the inclusive financial services ability in agriculture and rural areas}

Further promote diversified financial services such as financing, settlement, online banking, and wealth management to enter the households, serve the financing needs of the real economy and small and micro enterprises in rural areas, and implement the pricing principle of break- even and meager profit for rural inclusive loans, and minimize the farmers' financing costs and financial pressures. Vigorously develop agricultural and rural consumer finance business, support farmers' consumption upgrades, including consumer demand for housing construction, house purchase, car purchase, culture, education, health, etc., and comprehensively promote the development of inclusive financial business.

\subsubsection{Improvement of comprehensive service capabilities}

Commercial banks can provide customers with a comprehensive package of financial services including credit, investment, funds, insurance, leasing, and custody through extension of financial services by physical outlets and internet finance, to improve customer satisfaction and market competitiveness. Full advantages of commercial banks in financial assets management should be taken to help the people to achieve the growth of financial property income. For example, tailor-made comprehensive financial services should be provided to high-quality individual customers, such as civil servants, doctors, teachers, and staffs of state-owned enterprises, who have stable income and good credit. These will drive the overall improvement of personal quality financial services. Diversified financing methods should be explored and applied, such as unified 
lending, bond underwriting, PPP and government purchase services, and new financial instruments such as financial leasing, asset securitization, and collective notes should be innovated and applied through equity investment and investment-credit linkage to improve the supply of financial services.

\subsubsection{Strengthen cooperation with other financial institution}

Commercial banks can strengthen cooperation with professional banks such as CDB and Agricultural Development Bank, obtain agency business of CDB and Agricultural Development, conduct business cooperation in syndicated loans, industrial funds, investment and loan linkages, etc., and guide funds to be collected in commercial banks. Cooperation with other financial institution should be also strengthened, such as other banks, securities companies, insurance companies, fund companies, leasing companies, trust companies, to provide comprehensive and diversified financial tools and service channels for the market, and comprehensively enhance the financial service capabilities for rural revitalization.

\section{Conclusion}

According to statistics, the total capital demand for rural revitalization is over 7 trillion yuan, which will bring new business development resource for commercial banks in a new round of operation and development. To this end, banks must accelerate the development of agricultural and rural financial business by changing the thoughts of agricultural and rural financial development, improving the competitiveness of county-level channels, and innovating products and service systems, so as to effectively promote the development of rural agricultural economy.

\section{References}

[1] Jia, M.Q. and Li, C.Q. Reflections on the Operation Transformation of China's Commercial Banks from the Perspective of the New Bank Supervision Model [J]. South China Finance, 2011, (11): 27-31.

[2] Chen, Z.P., Xiao, J. and Li, C.Q. Reflections on Commercial Banks’ Development of Financial Technology in the New Situation [J]. International finance, 2018, (2): 37-41.

[3] Xie, J.H. and Li, C.Q. On the Bank Credit Entry Strategy in the New Situation [J]. South China Finance, 2009, (1): 58-60.

[4] Chen, Z.P., Huang, Z.Z., Xie, J.H., Li, C.Q. and Xiao, J. Research on the Status and Strategy of Commercial Banks' Development of Financial Technology [J]. Finance and Economy, 2019, (11): 22-28.

[5] Chen, Z.P., Li, C.Q., Wu, Y.Q., Xie, J.H. and Xiao, J. Analysis of Guangdong Commercial Bank’s Operational Transformation Based on the Guangdong-Hong Kong-Macao Greater Bay Area Strategy [J]. Guangdong Economy, 2018, (6): 50-57.

[6] Cai, S.J., Li, C.Q. and Xie, J.H. Reflections on Commercial Banks' Operational Transformation under the Development of Financial Technology [J]. Journal of ICBC Hangzhou Institute of Financial Studies, 2018, (7): 51-55. 